\title{
ARMAZENAMENTO DOS PRODUTOS PARA SAÚDE EM CENTROS DE ESTERILIZAÇÃO DE HOSPITAIS
}

Ivone Coutinho Mussel ${ }^{1}$, Adriana Oliveira de Paula², Adriana Cristina de Oliveira ${ }^{2}$

Objetivo: descrever condições de armazenamento dos produtos estéreis em Centros de Material Esterilizado de hospitais de grande porte. Metodologia: conduziu-se um estudo de abordagem quantitativa, realizada em dez hospitais de Belo Horizonte, entre maio e setembro de 2013. Para a coleta de dados utilizou-se um questionário estruturado e as análises por meio da estatística descritiva. Resultados: o acondicionamento do produto para saúde é feito em armários fechados (60\%), com revestimento lavável (100\%), com controle de umidade relativa do ar e temperatura. O controle da data de validade dos produtos foi referido em todos os centros de material e esterilização e o transporte em carros exclusivos em $80 \%$; $30 \%$ não possuíam área física exclusiva para produtos estéreis, armazenando-os junto a materiais não estéreis. Conclusão: Observou-se a necessidade uma maior atenção ao armazenamento do produto para saúde e ao cumprimento da legislação vigente.

Descritores: Armazenamento de Substâncias, Produtos e Materiais, Esterilização, Enfermagem, Segurança do Paciente.

\section{STORAGE OF HEALTH PRODUCTS IN HOSPITAL STERILIZATION CENTERS}

Objective: describe storage conditions for sterile products Sterilized Material Centers of large hospitals. Methodology: We conducted a study of quantitative approach, between May and September 2013 in ten hospitals. For data collection was used a structured questionnaire and analyzes using descriptive statistics. Results: the packaging of the medical device is given in closed cabinets (60\%), with washable lining (100\%), with control of relative humidity and air temperature. The control of the expiry date of the products mentioned in all material and sterilization centers and transport in exclusive cars by $80 \%$; $30 \%$ did not have exclusive physical area for sterile products, storing them together with non-sterile materials. Conclusion: There is a need for greater attention to the storage of the product for health and compliance with current legislation.

Descriptors: Storage of Substances, Products and Materials, Sterilization, Nursing, Patient Safety.

\section{ELALMACENAMIENTO DE PRODUCTOS SANITARIOS EN LOS CENTROS HOSPITALARIOS DE ESTERILIZACIÓN}

Objetivo: describir las condiciones de almacenamiento de los productos estériles esterilizadas los centros de material de grandes hospitales. Métodos: Se realizó un estudio de enfoque cuantitativo, entre mayo y septiembre de 2013 en diez hospitales. Para la recolección de datos se utilizó un cuestionario estructurado y los análisis por medio de la estadística descriptiva. Resultados: el envase del dispositivo médico se da en armarios cerrados (60\%), con revestimiento lavable (100\%), con control de la humedad relativa y la temperatura del aire. El control de la fecha de caducidad de los productos mencionados en todos los centros de material y esterilización y el transporte en automóviles exclusivos en un 80\%; 30\% no tenía espacio físico exclusivo para productos estériles, y los almacena junto con los materiales no estériles. Conclusión: Existe una necesidad de una mayor atención a la conservación del producto para la salud y el cumplimiento de la legislación vigente.

Descriptores: Sustancia de almacenamiento, Productos y materiales, Esterilización, Enfermería, Seguridad del Paciente. 


\section{INTRODUÇÃO}

O processamento de produtos para saúde (PPS) com qualidade, dentro das instituições de saúde, é uma importante medida de controle das infecções relacionadas à assistência à saúde. O produto para saúde, conforme a Resolução de Diretoria Colegiada (RDC) no15 de 2012, é aquele passivel de processamento, fabricados a partir de matérias primas especiais indicadas para uso em saúde, de conformação estrutural que permitem repetidos processos de limpeza, preparo e desinfecção ou esterilização, até que percam a sua eficácia e funcionalidade ${ }^{(1)}$.

Assim, o PPS implica em um conjunto de ações que se iniciam com a pré-limpeza, recepção, limpeza, secagem, avaliação da integridade e da funcionalidade, preparo, desinfecção ou esterilização, armazenamento e distribuição para as unidades consumidoras de forma que esse esteja pronto para o uso seguro ${ }^{(1-2)}$.

Todas as etapas do processamento devem ser rigorosamente realizadas almejando-se a garantia de um PPS isento de contaminante e que contribua para uma assistência segura ao paciente durante os procedimentos a serem realizados, sejam eles clínicos ou cirúrgicos ${ }^{(2-4)}$.

Estudos têm investigado a relevância de cada uma dessas etapas, sejam elas voltadas para a limpeza, métodos de processamento ou tempo de validade do produto na prateleira. Dentre outros aspectos, abordam como é feito - armazenamento do produto para saúde, que quando inadequado pode representar risco para a segurança da assistência prestada ao paciente $e^{(5-6)}$.

A validade do tempo de uso do produto na prateleira segundo a resolução no 15 de 2012 é a data limite de uso do produto esterilizado, ou seja, prazo adotado nas instituições, sustentado por um plano de avaliação fundamentado na integridade das embalagens, local de estocagem, condições de umidade e temperatura, segurança da selagem e rotatividade do estoque armazenado, garantindo seu uso seguro e confiável no atendimento ao paciente $\mathrm{e}^{(6-7)}$.

No entanto, mesmo que todas as etapas realizadas dentro do Centro de Material Esterilizado (CME) atendam aos padrões de qualidade e segurança, ainda assim, o produto para saúde estéril poderá estar comprometido caso, seu armazenamento não apresente garantias de manutenção da esterilidade como, por exemplo, a estocagem em gavetas, empilhamento de pacotes, dobras das embalagens, local não restrito e manipulação excessivaa ${ }^{(6,8)}$.

O local de guarda ou de armazenamento de material estéril no CME deve atender a padrões mínimos definidos e concernentes a esta prática relacionada à estrutura e área física, condições de temperatura, acesso, equipamentos e mobiliários ${ }^{(1.9)}$. Contudo, constata-se na literatura uma escassez de estudos que avaliem as condições dos locais de armazenamento do produto para saúde visando a manutenção de sua condição estéri( ${ }^{(5,10-12)}$.

Diante do exposto surgiu o seguinte questionamento: Quais as condições de armazenamento do produto para saúde esterilizado no centro de material esterilizado? Objetivou-se assim descrever as condições de armazenamento do PPS no CME, no que diz respeito à estrutura e organização da unidade.

\section{MÉTODOS}

Tratou-se de um estudo de abordagem quantitativa, realizado no centro de material e esterilização de hospitais de grande porte de Belo Horizonte, entre os meses de maio e setembro de 2013.

Foi identificado um total de 17 hospitais de grande porte, com capacidade de 150 a 299 leitos, segundo classificação da Portaria no 2.224/GM de 2002 $2^{(13)}$. Estes hospitais foram levantados de acordo com informações do Conselho Regional de Enfermagem de Minas Gerais, o qual possui um cadastro de todas as instituições, para identificação das CME existentes e com presença de um enfermeiro, registrado no conselho, para atuação na área do estudo.

Visitas às instituições foram agendadas e os enfermeiros atuantes no CME foram contatados e convidados a participar do estudo, em cuja oportunidade foi explicitada a importância da participação, o objetivo e relevância do trabalho.

Para autorização institucional, três tentativas consecutivas de contato foram realizadas. Foram excluídos os locais em que não foi possivel realizar o convite ou agendamento para a visita ao CME, ou quando informado que os hospitais terceirizavam o processamento de PPS.

Diante disso, das 17 instituições elegiveis como potenciais participantes, uma foi excluída por não realizar procedimentos cirúrgicos ou atendimento emergencial e, portanto, o CME não realizava o processamento de um volume considerável de materiais; três outras por dificuldade no contato telefônico e agendamento da visita; duas por impossibilidade de atender ao tempo da pesquisa para análise e aprovação junto ao Comitê de Ética local. Um dos hospitais compartilhava o processamento com outro da mesma rede hospitalar e com proximidade geográfica, o que levou a avaliação de 10 centros de materiais esterilizados dos 11 hospitais participantes do estudo. Para apontar as características específicas as instituições participantes estão referidas com as letras do alfabeto de $\mathrm{A}$ a J.

Para a coleta de dados utilizou-se um questionário estruturado, avaliado por cinco juízes, especialistas com reconhecimento no cenário nacional, quanto aos aspectos de abrangência, clareza, forma e adequação aos objetivos. $O$ instrumento foi construido com base nas resoluções 
da Agencia Nacional de Vigilância Sanitária- Anvisa(1,9). O mesmo foi dividido em duas partes: a primeira contendo questões sobre os padrões físicos gerais, específicos e estrutura organizacional exclusivamente no Centro de Material Esterilizado; a segunda parte com questões sobre recursos materiais e condições dos locais de armazenamento dos produtos para saúde estéreis. Dos dez CME que fizeram parte do estudo, o enfermeiro responsável pela unidade foi o respondente direto do instrumento.

As variáveis incluídas no instrumento se referiam às características dos locais de armazenamento do produto para saúde e da estrutura organizacional do CME da instituição, como área exclusiva para armazenamento de materiais estéreis, dimensionamento da área de armazenamento com base no quantitativo dos produtos recebidos, separação da área de armazenamento por barreira física das outras áreas do $\mathrm{CME}$, acesso restrito de funcionários à área de armazenamento, manutenção da porta fechada, presença de janelas lacradas, presença tubulações expostas, luz solar, ar condicionado, controle de temperatura, controle de umidade, tipos de armários do local de armazenamento (abertos, fechados, cestos), identificação das prateleiras, armários, cestos e gavetas do local de armazenamento, características da superfície (se material lavável), distância mínima de segurança para armazenamento dos materiais, rotina para a limpeza dos carros para transporte e a frequência com que era realizada.

Os dados foram analisados no programa estatístico Statistical Package for Social Science, versão 19.0 por meio da estatística descritiva, com apresentação de valores absolutos e porcentagens.

O estudo foi aprovado junto ao Comitê de Ética em Pesquisa da Universidade Federal de Minas Gerais, parecer: 255.424 .

\section{RESULTADOS}

Quanto à estrutura organizacional, seis (60\%) dos CME possuíam uma estrutura centralizada, três (30) semicentralizada e um (10\%) descentralizada.

As principais características dos locais de armazenamento do PPS estão apresentadas na Tabela 1.

Tabela 1 - Características dos locais de armazenamento do produto para saúde nos Centros de Material Esterilizado. Belo Horizonte, 2013

\begin{tabular}{|lll|}
\multicolumn{1}{|c}{ Caracteristicas } & \multicolumn{1}{|c}{$\begin{array}{c}\text { Sim } \\
\mathbf{n}(\%)\end{array}$} & $\begin{array}{c}\text { Não } \\
\mathbf{n}(\%)\end{array}$ \\
\hline Exclusivo para produtos estéreis & $7(70,0)$ & $3(30,0)$ \\
\hline $\begin{array}{l}\text { Dimensionamento adequado ao } \\
\text { quantitativo de produtos }\end{array}$ & $9(90,0)$ & $1(10,0)$ \\
\hline $\begin{array}{l}\text { Barreira física separando o local das } \\
\text { demais áreas do CME }\end{array}$ & $9(90,0)$ & $1(10,0)$ \\
\hline Acesso restrito & $9(90,0)$ & $1(10,0)$ \\
\hline Paramentação específica para o setor & $5(50,0)$ & $5(50,0)$ \\
\hline $\begin{array}{l}\text { Profissionais auxiliam em outras } \\
\text { atividades fora do arsenal }\end{array}$ & $4(40,0)$ & $6(60,0)$ \\
\hline $\begin{array}{l}\text { Porta permanece fechada a maior parte } \\
\text { do tempo }\end{array}$ & $9(90,0)$ & $1(10,0)$ \\
\hline Presença de janelas & $9(90,0)$ & $1(10,0)$ \\
\hline Presença de tubulações expostas & $1(10,0)$ & $9(90,0)$ \\
\hline Incidência de luz solar direta & $3(30,0)$ & $7(70,0)$ \\
\hline Presença de ar condicionado & $7(70,0)$ & $3(30,0)$ \\
\hline Controle de temperatura & $9(90,0)$ & $1(10,0)$ \\
\hline Controle de umidade & $9(90,0)$ & $1(10,0)$ \\
\hline
\end{tabular}

No que diz respeito à limpeza terminal do local de armazenamento do PPS estéril, destaca-se que 100\% dos enfermeiros informaram que esta era realizada semanalmente. Foi observado também em relação às janelas, das nove instituições que relataram sua presença, seis eram lacradas e em três eram mantidas fechadas e teladas.

Para as nove instituições que relataram possuir controle de umidade, a umidade relativa do ar variou entre 30 e $60 \%$ (TABELA 2). O controle de temperatura foi considerado quando da realização de anotações em impresso próprio, a partir da conferência e registro dos dados do termohigrômetro (dispositivo de parede que indica a temperatura e umidade relativa do ambiente) presente dentro do ambiente que se deseja controlar.

Tabela 2 - Faixa de umidade relativa do ar para cada instituição. Belo Horizonte, 2013

\begin{tabular}{|lcc}
\hline \multicolumn{1}{|c|}{ Faixa de umidade relativa } & N $(\%)$ & Hospitais \\
\hline 30 a $60 \%$ & $2(20)$ & E e I \\
\hline 34 a $60 \%$ & $1(10)$ & A \\
\hline 35 a $60 \%$ & $1(10)$ & D \\
\hline 40 a $48 \%$ & $1(10)$ & G \\
\hline 40 a $50 \%$ & $1(10)$ & H \\
\hline 40 a $60 \%$ & $1(10)$ & C \\
\hline $40 \%$ & $2(20)$ & B e J \\
\hline Não se aplica* & $1(10)$ & F
\end{tabular}

* Não havia verificação diária da temperatura e umidade do ar 
Em relação ao controle de temperatura, oito (80\%) das nove $(90 \%)$ instituições que conferiam a faixa de temperatura registraram valores entre $18 ㅇ$ C e $25 ㅇ ㅡ$, sendo que apenas uma ultrapassou esta temperatura, chegou a 29으.

A Tabela 3 apresenta a forma de armazenamento do PPS estéril, destacando-se que algumas áreas possuíam diferentes formas de acondicionar.

Tabela 3 - Formas de armazenamento do produto para saúde estéril no CME. Belo Horizonte, 2013

\begin{tabular}{|lcc|}
\multicolumn{1}{|c}{ Tipo de armazenamento } & $\operatorname{Sim} n(\%)$ & Hospitais \\
\hline Armários fechados & $6(60)$ & A, B, F, G H e J \\
\hline Armários abertos & $1(10)$ & F \\
\hline Prateleiras fechadas & $3(60)$ & A, D e I \\
\hline Prateleiras aramadas & $3(80)$ & C, E G \\
Cesto aramado & $4(70)$ & C, E, F e I
\end{tabular}

Dez (100\%) dos enfermeiros relataram que as superficies dos locais de contato direto do PPS estéril eram etiquetados e de revestimento lavável (sendo três de fórmica e sete de aço inoxidável). Todos respeitavam a distância mínima exigida pela legislação do teto de $45 \mathrm{~cm}$, em nove (90\%) a distância mínima do piso era de $20 \mathrm{~cm}$ e em oito (80\%) a distância mínima da parede de $05 \mathrm{~cm}$. No que diz respeito ao controle dos produtos estéreis, dez (100\%) relataram que conferem as das datas de validade da esterilização dos produtos armazenados e observam o manuseio mínimo dos materiais. Em oito (80\%) havia um inventário para controle do quantitativo dos produtos. Responderam haver um guichê exclusivo para distribuição do material.

Quanto aos carros para transporte de PPS estéril, todas as instituições o utilizam, sendo as características desses carros descritas na Tabela 4.

Tabela 4 - Características dos carros de transporte do produto para a saúde estéril no CME das instituições de estudo. Belo Horizonte, 2013

\begin{tabular}{|lcc|}
\multicolumn{1}{c}{$\begin{array}{c}\text { Caracteristicas dos carros de } \\
\text { transporte }\end{array}$} & $\operatorname{Sim} n(\%)$ & Hospitais \\
\hline Abertos & $4(40,0)$ & E, H, I e J \\
\hline Fechados & $5(50,0)$ & A, B, C, D e F \\
\hline Abertos e fechados & $1(10,0)$ & G \\
\hline Exclusivos para materiais estéreis & $8(80,0)$ & A, B, C, D, E, G, H e I \\
\hline Identificados corretamente & $7(70,0)$ & A, B, C, D, E, G e H
\end{tabular}

Ao avaliar a limpeza dos carros de transporte do PPS, a maioria sete $(70 \%)$ realizavam essa rotina, sendo em cinco com intervalos diários e duas semanais.

\section{DISCUSSÃO}

Falhas nas condições dos locais de armazenamento do produto estéril de saúde no CME foram verificadas podendo inferir riscos à esterilidade dos produtos, de acordo com as recomendações e legislações vigentes no Brasil(1,11). A exemplo, pode-se citar a guarda conjunta de materiais estéreis com não estéreis, prateleiras abertas, ausência de controle de umidade relativa e temperatura, incidência de luz solar direta no local e presença de tubulações expostas.

Considerando-se a estrutura organizacional observou-se umatendênciapelacentralização deprocessosnasinstituições pesquisadas. Tal cenário apresenta vantagens, uma vez que com a descentralização, parte do processamento (limpeza, desinfecção e empacotamento) é feito sem a supervisão direta do enfermeiro apenas com o encaminhamento dos produtos para a esterilização e armazenamento no centro de material esterilizado, podendo repercutir em potenciais falhas nessas etapas, considerando que o centro de material esterilizado não obtém total controle de todo o processo realizado(1,6,10).

De acordo com a legislação brasileira, o local de armazenamento e distribuição de produto para saúde no centro de material esterilizado deve ser dimensionado de acordo com o número de leitos da instituição(1,9). Deve ser centralizado em local exclusivo e de acesso restrito, não podendo ocorrer em área de circulação de pessoas, mesmo que temporariamente ${ }^{(9)}$. Em alguns centros de material esterilizado constatou-se a inobservância neste aspecto, devido à ampla e irrestrita circulação de toda equipe nesta área.

Outro aspecto se refere ao armazenamento exclusivo de produtos estéreis. Encontraram-se nesse estudo, em cerca de um terço das instituições que possuíam em seus arsenais, produtos não estéreis armazenados juntos aos estéreis. É inquestionável a importância de se evitar o cruzamento de produto estéril com não estéril, buscando garantir a manutenção da esterilidade do produto com as condições ideais de guarda obedecendo ao fluxo unidirecional dos $\operatorname{PPS}^{(1,8,10)}$.

Ainda, encontraram-se produtos armazenados em gavetas e armários considerados inadequados, com portas abertas, sem barreira física (separando-os de fluxos de produtos não estéreis), manipulados inadvertidamente por trabalhadores sem paramentação diferenciada. Tais características podem influenciar fortemente na validade da esterilização do produto de acordo com diversas associações internacionais ${ }^{(2,8,10)}$.

São aspectos vitais para manter as condições ideais de armazenamento do produto estéril para saúde: organização, 
limpeza e climatização do local de armazenamento(5). A variação brusca das faixas de umidade relativa e temperatura podem refletir na conservação das embalagens (secas ou úmidas), interferindo na resistência destes invólucros. A faixa de umidade relativa deve ficar entre $40 \%$ a $70 \%$, sendo permitidas adequações/ajuste de acordo com as diferenças climáticas regionais como muito quentes ou secas ${ }^{(2,8,10,14)}$.

A existência de um carro específico para o transporte do produto estéril é outro fator importante para preservar a esterilidade dos produtos. Os respondentes nesse estudo afirmaram atender aos requisitos mínimos de cuidados com limpeza dos carrinhos de transporte do PPS, cuidados estes indispensáveis para garantir a qualidade final do processo de esterilização ${ }^{(14)}$.

Dessa forma, observou-se neste estudo, assim como em outro realizado no Brasil, que as normas e legislações referentes aos temas de esterilização, principalmente no que diz respeito ao armazenamento de produtos para saúde esterilizados, não estão sendo atendidas na íntegra, indicando necessidade de maior observância das regulamentações e recomendações técnicas para essa atividade(11).

O delineamento das condições dos locais de guarda dos produtos estéreis para saúde foi bastante importante para se apontar que em grande parte das instituições participantes, inconformidades quanto às condições e características físicas do armazenamento do PPS estéril, referentes às exigências da legislação vigente e às recomendações dos órgãos regulamentadores de saúde, ainda não estão sendo totalmente cumpridas ou são desconhecidas pelos enfermeiros das unidades assistenciais. Apesar do seguimento de 11 instituições, considerada uma limitação do estudo, nos leva a refletir que possivelmente essa realidade não seria diferente em um quantitativo maior de avaliação de centrais de materiais esterilizado.

\section{CONCLUSÃO}

$\mathrm{Na}$ maioria dos CME, o acondicionamento do produto para saúde se deu em armários fechados, com revestimento lavável e em local com controle de umidade relativa do ar e temperatura. Entretanto, alguns não possuíam área física exclusiva para produtos estéreis, armazenandoos junto a materiais não estéreis. Constata-se que em relação às condições e características físicas do local de armazenamento do produto para saúde, as recomendações dos órgãos regulamentadores de saúde, associações nacionais e internacionais, ainda, não estão sendo cumpridas em sua totalidade nas unidades investigadas.

Os achados apontam para a necessidade de uma maior atenção na qualidade do armazenamento do produto para saúde estéril, a fim de preservar sua condição de esterilidade, garantindo seu uso seguro e livre de riscos para o paciente.

\section{REFERÊNCIAS}

1. Ministério da Saúde (BR). Agência Nacional de Vigilância Sanitária (ANVISA). Resolução № 15, de 15 março de 2012: Dispõe sobre requisitos de boas práticas para o processamento de produtos para saúde e dá outras providencias [Internet]. Brasilia, DF: ANVISA; 2012 [cited 2017 Dec 20]; Available from: https://www20. anvisa.gov.br/segurancadopaciente/index.php/legislacao/item/rdc-15-de-15-de-marco-de-2012

2. Rutala WA, Weber DJ. Assessing the risk of disease transmission to patients when there is a failure to follow recommended disinfection and sterilization guidelines. Am J Infect Control [Internet]. 2013 May [cited 2017 Dec 10]: 41(5):S67-S71. Available from: http://www.ajicjournal.org/article/S0196-6553(13)00013-8/pdf

3. Rutala WA, Weber DJ. Reprocessing semicritical items: Current issues and new technologies. Am J Infect Control [Internet]. 2016 [cited 2017 Dec 10]: 44(5):e53-e62. Available from: http://www.ajicjournal.org/article/S0196$6553(16) 00007-9 / p d f$

4. Alfa MJ. Current issues result in a paradigm shift in reprocessing medical and surgical instruments. Am J Infect Control [Internet]. 2016 [cited 2017 Dec 15]: 44(5):e41-e45. Available from: http://www.ajicjournal.org/article/S0196$6553(16) 00058-4 / p d f$

5. Kurniawansyah IS, Abdassah M. Gondodiputro SP. Relationship between Temperature and Humidity on Sterility of Reusable Instruments in Hospital's CSSD. Int J Pharm Sci [Internet]. 2015 [cited 2017 Dec 15]; 33(2):215-219. Available from: https://www.researchgate.net/publication/281603921_Relationship_between_temperature_and_humidity_on_sterility_of_medical_instruments

6. Sociedade brasileira de enfermeiros de centro cirúrgico, recuperação anestésica e centro de material e esterilização - SOBECC. Práticas recomendas. 6. ed. São Paulo, 2013.

7. Shaffer HL, Harnish DA, Mcdonald M, Vernon RA. Heimbuch BK. Sterility maintenance study: Dynamic evaluation of sterilized rigid containers and wrapped instrument trays to prevent bacterial ingress. Am J Infect Control [Internet]. 2015 [cited 2017 Dec 15]; 43(12):1336-41. Available from: http://www.ajicjournal.org/article/ S0196-6553(15)00761-0/pdf
8. Association for the advancement of medical instrumentation (AAMI). Comprehensive guide to steam sterilization and sterility assurance in health care facilities. AAMI: 2009

9. Ministério da Saúde (BR). Agência Nacional de Vigilância Sanitária (ANVISA) [Internet]. Resolução № 307, de 14 de novembro de 2002. Altera a Resolução - RDC no 50 de 21 de fevereiro de 2002: que dispõe sobre o Regulamento Técnico para planejamento, programação, elaboração e avaliação de projetos físicos de estabelecimentos assistenciais de saúde. Brasilia: Ministério da Saúde; 2002. [cited 2017 Dec 20]; Available from: http://portal.anvisa.gov.br/documents/33880/2568070/ RDC_307_2002.pdf/5el6cccf-2e72-42e8-ac9a-2ed25595443e

10. Association of operating room nurses (AORN) [Internet]. Recommended Practices for Sterilization in the Perioperative Practice Setting. In: AORN. Perioperative Standards and Recommended Practices. Denver: 2012. [cited 2017 Dec 20]: 83(3):700-22. Available from: https://aornjournal.onlinelibrary.wiley.com/doi/ pdf/10.1016/S0001-2092\%2806\%2960198-1

11. Freitas LR, Tipple AFV, Pires FV, Melo DS, Spagnoli JLU. (Lack of) care for sterilized healthcare products during transport to and storage in inpatient units. Texto contexto - enferm. [Internet]. 2015 Mar [cited 2017 Dec 20]: 24(1): 253-262. Available from: http://www.scielo.br/pdf/tce/v24nl/0104-0707-tce-24-01-00253.pdf

12. Seavey R. Troubleshooting failed sterilization loads: Process failures and wet packs/load. Am J Infect Control [Internet]. 2016 [cited 2017 Dec 20]; 44(5):e29-e34. Available from: http://www.ajicjournal.org/article/S0196-6553(16)00201-7/pdf 13. Ministério da Saúde (BR) [Internet]. Portaria no 224/ GM, de 5 de dezembro de 2002. Dispõe sobre o sistema de Classificação Hospitalar do Sistema Único de Saúde. Brasilia: Ministério da Saúde; 2002. [cited 2017 Dec 20]. Available from: http://www.husm.ufsm.br/janela/legislacoes/urgencia-emergencia/urgencia-emergencia/portaria-no-2224gm-em-5-de-dezembro-de-2002.pdf

14. Williamson JE. Sterility in supply storage areas. Healthcare purchasing news. In: International Association of Healthcare Central Service Material Management (IAHCSMM). Annual Meeting. Louisville, K.Y. August. 2013. 